\title{
Fragility analysis of the self-centering prestressed concrete frame with web friction devices
}

\author{
Lianglong Song ${ }^{1, *}$, Xin $\mathrm{Shi}^{2}$, Tong $\mathrm{Guo}^{2}$ and Pengfei $\mathrm{Zhu}^{1}$ \\ ${ }^{1}$ College of Civil and Transportation Engineering, Hohai University, China \\ ${ }^{2}$ School of Civil Engineering, Southeast University, China
}

\begin{abstract}
A novel self-centering prestressed concrete (SCPC) beam-column connection with web friction devices has been recently proposed for moment-resisting concrete frames. This paper presents the fragility analysis results of a SC concrete frame and a conventional reinforce concrete (RC) frame at various performance levels. Three performance limit states (i.e., Immediate Occupancy, Life Safety and Collapse Prevention limit states) are defined based on the peak story drift ratio and two other performance limit states (i.e., Re-centering and Repairable limit states) are defined based on the residual story drift ratio. Statistical analyses of the seismic demands reveal that the SC frame reduces the softening and dispersion of the residual story drift behavior. Fragility curves indicate that the SC frame experiences much smaller residual deformations and shows considerable reduction in the median fragility and probability of exceedance for the residual drift-related performance levels, as compared with the conventional RC frame.
\end{abstract}

\section{Introduction}

Recent seismic events have highlighted the limitations of the current building code provisions, in which the conventional reinforced concrete (RC) moment-resisting frames (MRFs) are expected to sustain significant residual deformations and structural damage after strong earthquakes. Post-earthquake field reconnaissance revealed that many seismically damaged RC frame structures were demolished, even though they did not experience severe structural damage or collapse [1].

The research efforts on self-centering (SC) concrete frames have shown that they sustain much less residual deformations as compared with the conventional RC frames [2-5]. Fig. 1 shows a novel self-centering prestressed concrete (SCPC) frame with web friction devices (WFDs) recently proposed by Song et al. [6]. The behavior of an SCPC frame is characterized by the gap opening/closing at the beam- column interfaces. An SCPC frame with WFDs uses unbonded post-tensioned (PT) tendons to compress the precast beam and column together, and to provide an elastic restoring force that returns the frame to its initial position (i.e. the frame is "self-centering") after earthquakes. Steel jackets and steel plates are shop fabricated at the beam ends and columns to prevent the concrete at the beam-column interface from damage. WFDs are installed at the beam ends to increase the energy dissipation capacity. The WFD consists of two steel channels bolted to the column using the high strength connection bolts. The steel channels are compressed to the steel jacket using the friction bolts, which can provide normal forces on the friction surfaces. Sandwiched between the steel channels and the steel jacket are brass friction plates adhered to the inner surfaces of the channels. The diameter of the oversized circular bolt ducts in the steel jacket and concrete beam is much larger than that of the friction bolts to accommodate the motion of friction bolts when the beam rotates relative to the column.

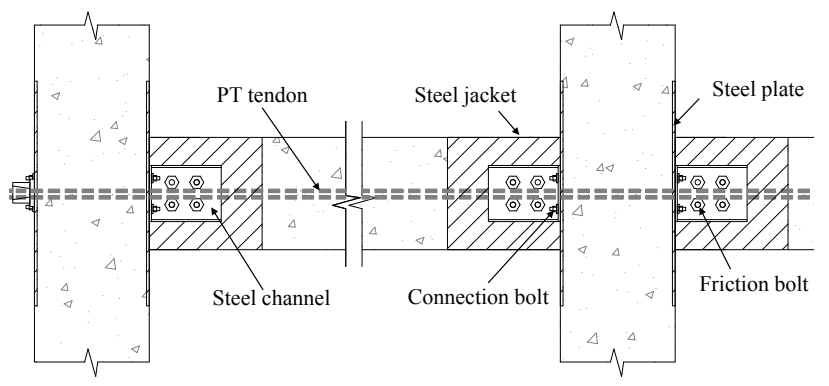

(a) Profile of the SCPC frame

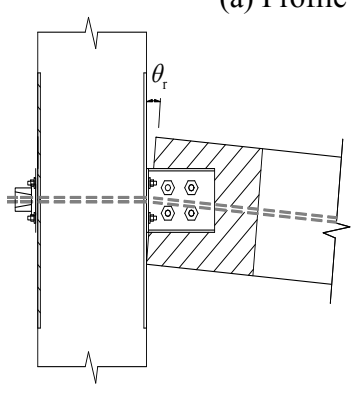

(b) Gap-opening

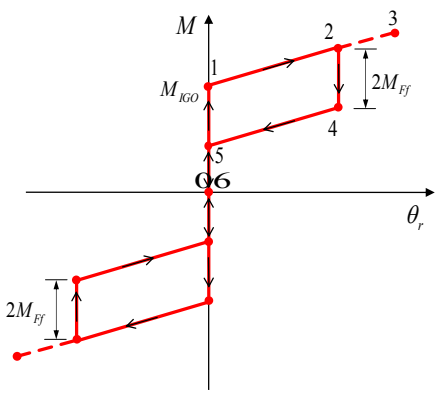

(c) $M-\theta_{r}$ behavior
Fig. 1. SCPC frame with web friction devices

A conceptual connection moment-relative rotation $\left(M-\theta_{r}\right)$ behavior is shown in Fig. 1(c), The beam-column interface is in complete contact until the applied external moment exceeds the imminent gap-opening moment

\footnotetext{
Corresponding author: songll@hhu.edu.cn
} 
$M_{I G O}$ (at event 1), which is equal to the sum of $M_{P T}$ and $M_{F f}$, representing the moment resistance of the initial PT force and friction force, respectively. The ratio of $M_{F f}$ and $M_{I G O}$ is equal to the connection's hysteretic energy dissipation ratio $\beta_{E}$ [6]. As the load increases, gapopening occurs and the PT tendons elongate to produce additional PT forces. If unloading occurs at event $2, \theta_{r}$ remains constant and the WFDs will dissipate energy (between events 2 and 5) until the gap is closed at event 5 . The connection moment decreases between events 5 and 6 , and the connection returns to its original position at event 6 , when the connection self-centers. A complete reversal of the applied moment will lead to a similar connection behavior in the opposite direction of loading.

In this study, fragility analyses are conducted to evaluate the seismic performance of the SCPC frame with WFDs. Two demonstration concrete frames (i.e. the conventional RC frame and the SCPC frame) are designed and analyzed by performing the seismic fragility analyses so as to provide a quantitative comparison of the probabilistic performance of the two frame systems.

\section{Structural models}

\subsection{Prototype building}

The 4-story, 3-bay RC frame (Fig. 2) created by Haselton et al. [7] is selected as the prototype structure. The building was designed as a special RC moment resisting frame structure following the 2003 International Building Code, ASCE 7-02 and ACI 318-02, with design details associated with the ductile $\mathrm{RC}$ frame. The building was assumed to be located on a stiff soil site in the LA Bulk Mail facility in Bell, California. A force reduction factor $R$ of 8 and a deflection amplification factor $C_{\mathrm{d}}$ of 5 were used for the $\mathrm{RC}$ frame. Beam strengths were controlled by gravity and lateral force demands, and column strengths were governed by the strong-column weakbeam requirements. Beam transverse reinforcements were controlled by shear capacity design, and column stirrups were controlled by both shear capacity design and confinement requirements. The cross-sectional dimensions of beams and columns of the $\mathrm{RC}$ frame are shown in Fig. 2, and more design details can be found in Haselton et al. [7].

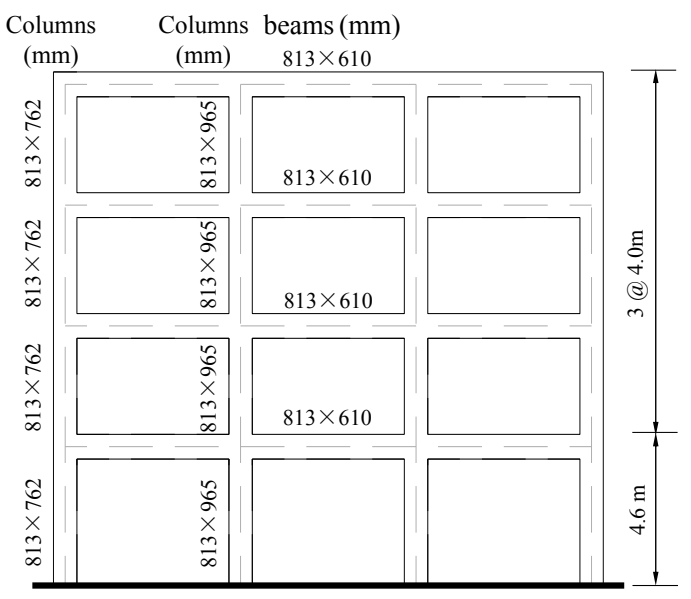

Fig. 2. The elevation view of the prototype RC frame
In this study, to allow for a direct comparison with the $\mathrm{RC}$ frame, the SC frame is designed with the same beam/column sizes and column reinforcement ratios as those of the RC frame. The design imminent gap opening moment demand at the beam ends, $M_{I G O}$, is set equal to the average value of the positive and negative strength demands at the corresponding beam ends of the $\mathrm{RC}$ frame. Beam reinforcement ratios are determined according to constructional reinforcement ratio (i.e., $0.5 \%$ ), as suggested in Song et al. [6]. Table 1 summarizes the design details of SCPC connections at all floors, including the number of PT tendons, $N_{S}$, the initial PT force, $T_{0}$, and the friction force on web friction devices, $F_{f}$. The PT tendons are placed at the beam centroid. A value of 0.48 is assumed for $\beta_{E}$ to determine the value of $T_{0}$ and $F_{f}$. Based on the design yield strength, $f_{p y}$ (i.e., $1675 \mathrm{MPa}$ ), and the cross-sectional area (i.e., $139 \mathrm{~mm}^{2}$ ) of the PT tendon, $N_{S}$ can be determined through $T_{0}$ and a design initial PT tendon stress $f_{p i}=0.50 f_{p y}$.

Table 1. Design Characteristics of SCPC connections.

\begin{tabular}{|c|c|c|c|}
\hline Floor & $N_{S}$ & $T_{0}(\mathrm{kN})$ & $F_{f}(\mathrm{kN})$ \\
\hline 1 & 27 & 2074 & 1915 \\
\hline 2 & 25 & 1945 & 1795 \\
\hline 3 & 24 & 1823 & 1683 \\
\hline 4 & 14 & 1042 & 962 \\
\hline
\end{tabular}

\subsection{Analytical models}

Nonlinear time-history analyses are performed using the finite element analysis program OpenSees. A twodimensional plane frame consisting is modeled and analyzed in this study. Fig. 3 shows a schematic representation of the SCPC connection model described in Song et al. [6]. The beam-column interface was modeled using two pairs of rigid beam-column elements. The gap opening/closing at the beam-column interface was modeled using a pair of zeroLength contact elements with compression only material properties. The beam-column panel zone was modeled using a group of rigid elasticbeamcolumn elements located at four sides of the panel zone and a rotational spring located at one of the four corners. The steel channel was modeled using an elasticBeamColumn element. The friction force was modeled using a zeroLengthSection element incorporated with bi-directional plasticity property. The PT tendons were modeled using truss elements and a bilinear material model with an initial strain was applied to the truss element.

The beams and columns of both the RC and SC frames were modeled using the distributed plasticity fiber elements which can capture the distribution of inelasticity across the depth of the section and the length of the structural member. Each section of the members was subdivided into a number of fibers which are assigned with the uniaxial stress-strain relationships of the materials. For simplicity, shear deformation in the panel zone of the RC frame was modeled using an elastic joint shear panel spring. The Giuffre-Menegotto-Pinto hysteretic material in OpenSees was used to model the reinforcing steel. The transverse confinement effect to 
the core concrete of the members was accounted for by increasing strength and deformation capacity of concrete using the Kent-Scott-Park model [8]. Rayleigh damping was applied with a damping ratio of $5 \%$ specified at the first and third structural modes. In order to capture the residual deformations, all analyses were performed with additional zero acceleration values padded to the ground motion records to allow the free vibration decay of the structure.

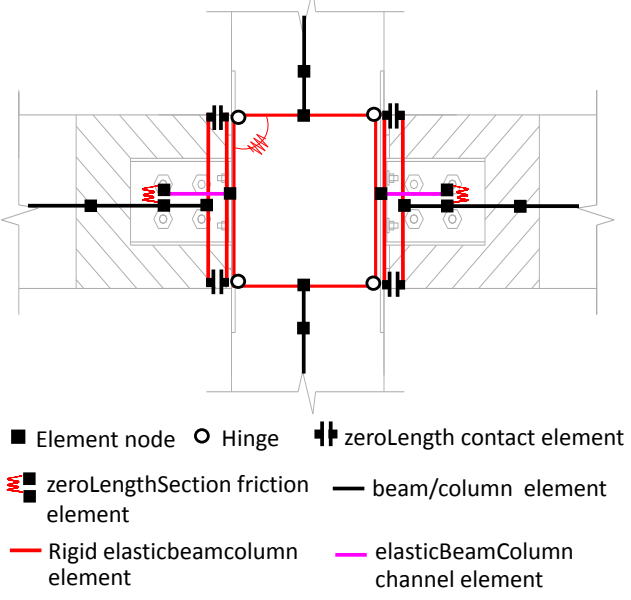

Fig. 3. OpenSees model of SCPC connection

\section{Earthquake ground motions}

Ten pairs of far-fault earthquake ground motions (Table 2) from the PEER ground motion database are used for nonlinear time-history analyses. The ground motions had been rotated to fault-normal (FN) and fault-parallel (FP) components. The selection of the ground motions are based on the stiff soil type, and they have different peak ground accelerations, the first-mode spectral acceleration at $5 \%$ damping ratio, $S_{a}\left(T_{1}, 5 \%\right)$, the magnitude and durations, so as to investigate the influence of uncertain earthquake input.

Table 2. Characteristics of selected earthquake records.

\begin{tabular}{|c|c|c|c|c|}
\hline No. & Event & Year & Station & Magnitude \\
\hline 1 & $\begin{array}{c}\text { Imperial } \\
\text { Valley-06 }\end{array}$ & 1979 & Delta & 6.53 \\
\hline 2 & $\begin{array}{c}\text { Superstition } \\
\text { Hills-02 }\end{array}$ & 1987 & $\begin{array}{c}\text { Westmorland } \\
\text { Fire Sta }\end{array}$ & 6.54 \\
\hline 3 & $\begin{array}{c}\text { Kocaeli- } \\
\text { Turkey }\end{array}$ & 1999 & Zeytinburnu & 7.51 \\
\hline 4 & Landers & 1992 & Amboy & 7.28 \\
\hline 5 & $\begin{array}{c}\text { Chi-Chi- } \\
\text { Taiwan }\end{array}$ & 1999 & HWA043 & 7.62 \\
\hline 7 & $\begin{array}{c}\text { Northridge-01 } \\
\text { Northridge-01 }\end{array}$ & 1994 & $\begin{array}{c}\text { LA-Pico \& } \\
\text { Sentous }\end{array}$ & 6.69 \\
\hline 9 & $\begin{array}{c}\text { Superstition } \\
\text { Hills-02 }\end{array}$ & 1987 & $\begin{array}{c}\text { LA-Century } \\
\text { City CC North }\end{array}$ & 6.69 \\
\hline 10 & $\begin{array}{c}\text { Krawley } \\
\text { Airport }\end{array}$ & 6.54 \\
\hline Turkey & 1999 & $\begin{array}{c}\text { Duzce } \\
\text { Osage Ave }\end{array}$ & 6.69 \\
\hline
\end{tabular}

\section{Response statistics}

The incremental dynamic analysis (IDA) procedure was performed by scaling the ground motions to increasing levels of $S_{a}\left(T_{1}, 5 \%\right)$. The analysis results from the IDA are shown in Figs. 4 and 5. The maximum and residual story drifts of the SC and RC frames for each ground motion are shown at each intensity level. The median values of story drifts are shown with a solid line and the 16 th and 84 th percentile values are shown with dashed lines. The maximum story drift responses of the SC and $\mathrm{RC}$ frames both exhibit a bit of softening with increasing seismic intensity level. In general, there is no significant difference in terms of the general trend regarding the maximum story drifts of the SC and RC frames. The median maximum drift demands of the $\mathrm{SC}$ frame for the $10 \%$ and $2 \%$ probabilities of exceedance (PE) in 50 -year hazard level are $1.63 \%$ and $2.95 \%$, respectively, while the values of the RC frame are $1.51 \%$ and $3.02 \%$, respectively. The dispersion of maximum story drift demands is $20.54 \%$ for the SC frame, while the RC frame had a slight increase $(23.30 \%)$ in the dispersion of maximum story drifts.

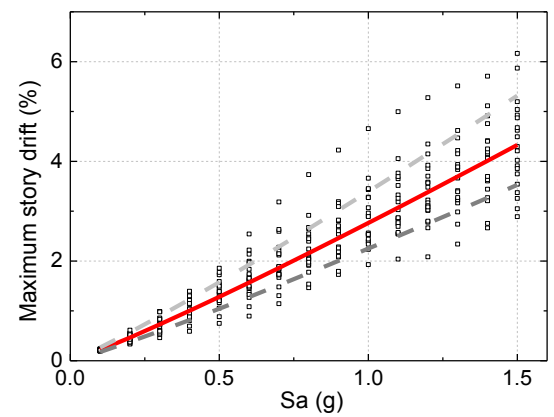

(a) SC frame

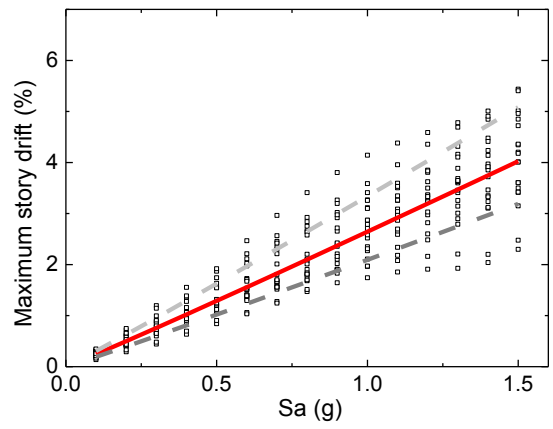

(b) RC frame

Fig. 4. Maximum story drifts of the SC and RC frames

As shown in Fig. 5, the residual story drifts of the RC frame soften much faster and experience larger increase with increasing seismic intensity level, when compared to the SC frame. The median residual story drift demands of the SC frame for the $10 \%$ and $2 \%$ PE in 50 year hazard level are $0.04 \%$ and $0.18 \%$, respectively, while the values of the RC frame are $0.16 \%$ and $0.48 \%$, respectively. For both the $\mathrm{SC}$ and $\mathrm{RC}$ frames, the dispersion of residual story drift demands is much larger than that of maximum story drift demands. The dispersion of residual story drift demands is $77.94 \%$ for the SC frame, while the value is $89.69 \%$ for the $\mathrm{RC}$ frame. 


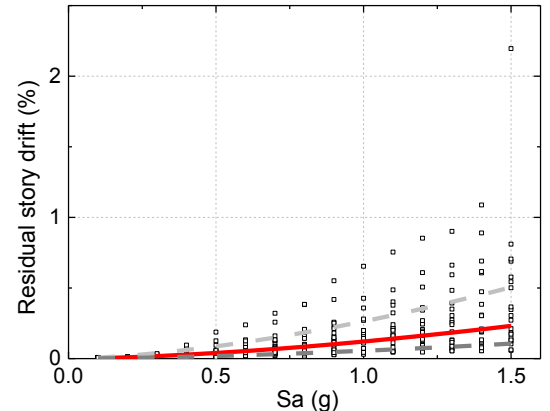

(a) SC frame

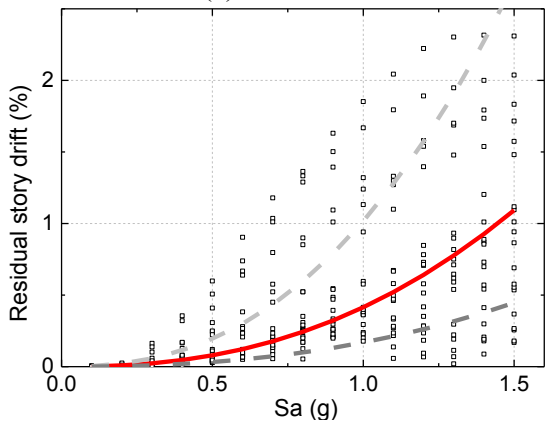

(b) RC frame

Fig. 5. Residual story drifts of the SC and RC frames

\section{Seismic fragility analysis}

\subsection{Definition of limit states}

The performance limit states chosen for fragility analysis can be identified by different levels of engineering demand parameters. According to ASCE/SEI 41-06, three structural performance levels are adopted in this study, namely, Collapse Prevention (CP), Life Safety (LS) and Immediate Occupancy (IO) performance levels, with corresponding maximum allowable story drift ratios of $4 \%, 2 \%$ and $1 \%$, respectively.

To assess the possible benefits of reduced residual deformations of the SC frame, two performance levels associated with the residual story drift ratio are used, i.e., "Re-centering" and "Repairable" performance levels, with corresponding maximum allowable residual story drifts of $0.2 \%$ and $0.5 \%$, according to the study in Song et al. [9]. The "Re-centering" performance level is a damage state where the structure can return to its original vertical alignment with minimal residual drift. The "Repairable" performance level is a damage state where the structure suffers certain damage and it may be financially more feasible to repair the structure than to demolish it.

\subsection{Fragility analysis results}

The seismic fragility curves of the SC and RC frames are presented in Fig. 6. The parameters used in the fragility formulation for each frame are summarized in Table 3. As seen in Fig. 6(a), the fragilities of the two frames are similar for the IO, LS and CP performance levels. As listed in Table 3 , the median fragility values $\left(m_{R}\right)$ of both frames are essentially the same for the IO performance level, and the values of the RC frame are slightly larger than those of the SC frame for the LS and CP performance levels. The dispersion $\left(\beta_{R}\right)$ in the fragility of the SC frame is smaller than that of the RC frame for all the three performance levels. The similar fragility of the two frame systems for the IO, LS and CP performance levels indicates that the SC frame can perform as well as the $\mathrm{RC}$ frame, as the post-earthquake repair costs of the $\mathrm{SC}$ frame due to the maximum drift-related damage are comparable to those of the RC frame.

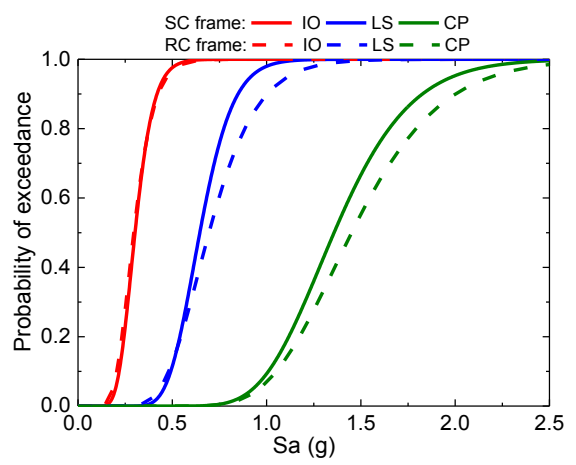

(a) IO, LS and CP limit states

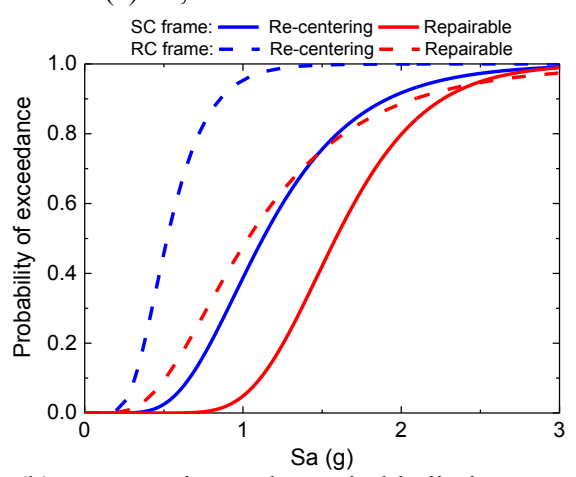

(b) Re-centering and Repairable limit states

Fig. 6. Fragility curves for the SC and RC frames

Fig. 6(b) shows the seismic fragility curves corresponding to the two performance levels based on the residual story drift. The fragility curves for the $\mathrm{RC}$ frame "shifts to the left" of the curves for the SC frame, which implies that the RC frame is more vulnerable than the SC frame for the "Re-centering" and "Repairable" performance levels. For example, the median fragility values for the RC frame are $0.521 \mathrm{~g}$ and $1.032 \mathrm{~g}$ for the "Re-centering" and "Repairable" performance levels, respectively, compared with $1.126 \mathrm{~g}$ and $1.586 \mathrm{~g}$ for the $\mathrm{SC}$ frame. The significant improvement of fragility for the "Repairable" performance level reveals that the SC frame can effectively reduce the downtime losses arising from the required demolition and replacement of the structure, which is due to the unacceptable large residual deformations.

Table 3. Parameters used in the fragility formulation

\begin{tabular}{ccccc}
\hline \multirow{2}{*}{$\begin{array}{c}\text { Performance } \\
\text { levels }\end{array}$} & \multicolumn{2}{c}{ RC frame } & \multicolumn{2}{c}{ SC frame } \\
\cline { 2 - 5 } & $m_{R}(\mathrm{~g})$ & $\beta_{R}$ & $m_{R}(\mathrm{~g})$ & $\beta_{R}$ \\
\hline IO & 0.296 & 0.285 & 0.302 & 0.255 \\
LS & 0.695 & 0.287 & 0.646 & 0.213 \\
CP & 1.451 & 0.251 & 1.358 & 0.231 \\
Re-centering & 0.521 & 0.387 & 1.126 & 0.414 \\
Repairable & 1.032 & 0.549 & 1.586 & 0.278 \\
\hline
\end{tabular}




\section{Conclusions}

In this paper, a self-centering (SC) concrete frame, which uses a recently developed self-centering prestressed concrete (SCPC) beam-column connection, is proposed to mitigate the residual deformations in the frame structure. To evaluate the performance of the proposed system, two benchmark concrete structures, either using the conventional reinforced concrete (RC) frame or the self-centering (SC) concrete frame, are designed, modeled and assessed using the probabilistic seismic performance evaluation techniques. Incremental dynamic analysis has been performed to estimate the seismic demands using a suite of selected earthquake records. Seismic fragility analyses are then conducted to make a quantitative comparison of the relative performance of the RC and SC frames. Based on the presented analysis results, the following conclusions can be drawn:

(1) The SC frame can perform well, experiencing similar maximum story drift demands as compared with the conventional RC frame, while with significantly reduced residual story drift demands. Statistical analyses of the seismic demands reveal that the SC frame reduces the softening and dispersion observed in the residual story drift behavior. In addition, it is found that the dispersion of residual story drift demands is larger than that of maximum story drift demands for both frames.

(2) Seismic fragility analysis results reveal that the RC and SC frames have similar median fragility values and limit state exceedance probabilities for the IO, LS and CP performance levels, due to the fact that they have similar maximum story drift demands.

(3) Compared with the RC frame, the SC frame is found to have much smaller median fragility values and limit state exceedance probabilities for the "Recentering" and "Repairable" performance levels.

The support from: (1) the National Natural Science Foundation of China under Grants No. 51708172 and 51378107; (2) Natural Science Foundation of Jiangsu Province under Grant BK20170890; and (3) Fundamental Research Funds for the Central Universities under Grant 2016B14714 is gratefully acknowledged.

\section{References}

1. K.C. Tsai, C.P. Hsiao, M. Bruneau, Earthq. Eng. Eng. Seismol. 2, 93(2000)

2. M.J.N. Priestley, G. MacRae, PCI J. 41, 64(1996)

3. W.C. Stone, G.S. Cheok, J.F. Stanton, ACI Struct. J. 92, 229 (1995)

4. L. Li, J.B. Mander, R.P. Dhakal, J. Struct. Eng. 134, 1733 (2008)

5. B.G. Morgen, Y.C. Kurama, PCI J. 49, 112(2004)

6. L.L. Song, T. Guo, C. Chen, Earthq. Eng. Struct. Dyn. 43, 529(2014)

7. C.B. Haselton, A.B. Liel, G.G. Deierlein, B.S. Dean, J.H. Chou, J. Struct. Eng. 137, 481(2010)

8. D.C. Kent, R. Park, J. Struct. Div. 97, 1969(1971)

9. L.L. Song, T. Guo, Z.L. Cao, Soil Dyn. Earthq. Eng. 71, 151(2015) 